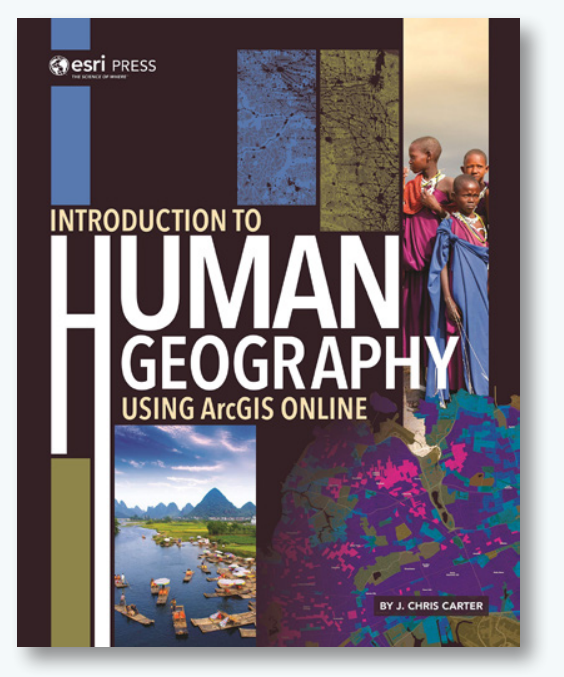

\title{
INTRODUCTION TO HUMAN GEOGRAPHY USING ARCGIS ONLINE
}

\author{
By J. Chris Carter
}

Esri Press, 2019

427 pages

Softcover: \$74.99, ISBN 978-1-58948-518-1

Review by: John T. Bauer, University of Nebraska at Kearney

Esri Press has been publishing educational books about Esri products for many decades. I remember being assigned Understanding GIS: The ArcINFO Method over twenty years ago in college, and more recently Esri Press has expanded its catalog to include textbooks for cartography, remote sensing, and other GIScience areas. Introduction to Human Geography Using ArcGIS Online, authored by J. Chris Carter, is its first textbook for an introductory non-GIScience geography course. The blurb on the book's back cover describes it as "a one-of-a-kind introductory textbook aimed at college undergraduates and high school advanced-placement students"-one that "bridges classroom lecture with live, current, interactive data for reinforced learning and a hybridized teaching approach." "With this book," they tell us, "instructors can tailor classroom examples and homework assignments to local geography." Carter is a professor of geography at Long Beach City College in California, where he teaches human geography and geographic information systems. His training and experience in both human geography and GIS make him ideally suited for writing this text.

Like other introductory human geography textbooks, this book is organized into topical chapters, each between thirty and forty pages long. Chapter 1 provides readers with an introduction to both the discipline of human geography and important concepts of GIS online mapping. Topics covered include space, place, region, spatial diffusion, human-environment interaction, geographic data sources, map scale and accuracy, map types, and coordinate systems.
Chapters 2, 3, and 4 are titled "Population," "Migration," and "Race and ethnicity," respectively. Chapter 2 explains such basic demographic indicators as crude birth rate, total fertility rate, and rates of natural increase. It also covers population pyramids, dependency ratios, and the concept of demographic dividend. Some population theory is also included, with discussions of the demographic transition model and of Malthusian theory. Chapter 3 expands upon the basic demography concepts from Chapter 2 with a thorough overview of migration, and it clearly explains topics such as a migrant stock and flow, push and pull forces, government immigration policies, the impacts of migration, and migration gravity modeling. The concepts of race and ethnicity are carefully explored in Chapter 4, as is the spatial distribution of racial and ethnic minorities in the United States. The author explains how geographers have studied racial and ethnic discrimination using methods such as hot spot analysis, the location quotient, the index of dissimilarity, market segmentation analysis, and tapestry segmentation.

"Urban geography" is the title of Chapter 5. After a definition of urbanization and a short historical discussion of the origin and growth of the city, Carter launches into an extensive explanation of the distribution of cities, both at the global and regional scales. The rank-size rule (Zipf's law), central place theory, and the concepts of site and situation are all introduced as theories geographers have used to explain and model urban population distributions. Next, the author turns to the models used to describe the spatial organization of cities, such as sector, multiple-nuclei, and 
concentric rings. Related topics such as urban and suburban growth and decline, zoning, smart growth, and urbanization in developing regions are also briefly touched upon.

Concepts in economic geography form the subjects of Chapters 6, 7, and 8. Food and agricultural productionthe primary sector of the global economy-is covered in Chapter 6. The chapter begins with an historical overview of the first (or Neolithic) agricultural revolution, plant domestication, the fifteenth- and sixteenth-century Columbian exchange, and the second agricultural revolution of the mid-seventeenth to late nineteenth centuries. As has been his pattern in earlier chapters, Carter follows this introduction with a detailed analysis of the spatial distribution of agricultural activity, including commercial, subsistence, and plantation farming. Hunger and food security, food deserts, and food loss and waste conclude the chapter. The geography of manufacturing, representing the secondary sector of the economy, is covered in Chapter 7. Beginning at the Industrial Revolution, the chapter explains the spatial distribution of manufacturing along with the various factors that drive industrial location-including the theories of Alfred Weber: for example, that firms seek out factory sites that minimize transport and labor costs-and segues into the contemporary changes in industrial production in the United States, Europe, and the developing world. The service, or tertiary, sector of the economy is the subject of Chapter 8. As in Chapters 6 and 7, Carter begins with a bit of history before turning to spatial distributions, utilizing location theory and central place theory where applicable. The chapter ends with a discussion of service employment through the topics of automation, inequality, universal basic income, and labor unions.

In Chapter 9, Carter examines the geography of human development, starting with a definition of development and an overview of the basic development indicators such as gross national income, life expectancy, a gender inequality index, and the human development index. Wellknown theories of development are explained, including exploitation-based theories such as dependency theory, and market-based theories such as modernization theory and neoliberalism.

Chapter 10, "Cultural geography-folk and popular culture, language, religion," begins with a discussion of cultural regions in the United States and demonstrates how tapestry segmentation analysis can be used to determine their extents. The discussion of folk and popular culture focuses on music, food, and housing. An analysis of linguistic and religious geographies, using both American and international examples, forms the bulk of the chapter. Topics include language development and language families, dialects, lingua francas, endangered languages, ethnic and universalizing religions, intolerance, and religious persecution.

The wide-ranging subfield of political geography is the subject of Chapter 11. Electoral geography (including gerrymandering), the concepts of nation and state, state border issues, the size and shape of countries, unitary and federal states, authoritarianism and democracy, centripetal and centrifugal forces, balkanization, terrorism, and supranational organizations are just a sample of the plethora of topics covered in this long chapter.

The final chapter of the book, Chapter 12, is about human-environment interaction, focusing on pollution and climate change. After introducing the concept of the Anthropocene (or the human-recent) epoch, Carter examines air, water, and solid waste pollution and discusses sources, temporal trends, spatial patterns, and solutions for each. The chapter concludes with a discussion of the causes and consequences of global climate change, and its impacts on human geographies.

A unique feature of this textbook-one that sets it apart from other human geography texts-is the inclusion of sixty-two hands-on ArcGIS Online exercises that span topics in all twelve chapters. The exercises are available as PDF files (almost 400 pages total) on the Esri Press website and contain step-by-step instructions along with gradeable questions to assess progress. I could not find an answer key for these questions, so I assume that the instructor has to complete the exercises themselves before grading. Purchase of the textbook provides students with a 180-day free trial of ArcGIS Online, access to the ArcGIS Living Atlas of the World, and 200 ArcGIS Online service credits.

At over 425 pages, the book is thicker than most introductory human geography textbooks, but at least some of that bulk is because its text is set in 11-point type and because it contains hundreds of large, full-color charts, tables, diagrams, photographs, and historic maps, as well as many custom ArcGIS Online maps. All of these are available 
as projection-quality downloads from the Esri Press website, a resource facilitating high-quality classroom lecture presentations. The custom ArcGIS maps are a particular strength of the book. Each has a URL that connects to the live map resource on ArcGIS Online, where the student can manipulate the map and interactively explore the data behind it. Each chapter includes a list of about thirty to fifty references for further reading. These references are relevant, current, and easily accessed via URL or DOI number. Curiously, the review copy that was provided did not include a table of contents or a preface, but I was able to download the table of contents from the book's webpage at the Esri Press website (esripress.esri.com). The preface was not available for download, so I could not include it in this review.

Not surprisingly, because of its integration with ArcGIS Online, the textbook provides a very numerical, spatial, and model-driven approach to human geography. Many of the theories presented in the chapters are commonly used in GIS analysis and originated decades ago during geography's Quantitative Revolution. This is not a social theory text with introductions to the many French theorists that have influenced some contemporary geography circles, and Marxists, feminists, postcolonialists, and other critical human geographers will probably find the text unattractive.

Overall, Introduction to Human Geography using ArcGIS Online is an excellent textbook. The writing is clear and concise, and the examples and issues given in the book are current and relevant. Although the majority of the examples and topics are of North American human geography, Professor Carter does add some international subjects with geographies from Europe, Asia, Latin America, and Africa. Thus, this is not a book about the human geography of the United States, or even of the World, but one about human geography in general. Although introduction to human geography is not a current teaching assignment of mine, I will seriously consider adopting this book if my assignments change in the near future. 